\title{
Top-down Production Management: A Recent Trend in the Japanese Productivity-enhancement Movement
}

\author{
W. Mark Fruin ${ }^{1}$ and Masao Nakamura ${ }^{2 *}$ \\ ${ }^{1}$ Michigan Business School, University of Michigan, USA \\ ${ }^{2}$ Institute of Asian Research and Faculties of Commerce and of Applied Science, University of British Columbia, Canada
}

\begin{abstract}
It is well known that many of the manufacturing practices advanced in Japan in the 1970s and 1980s emphasize bottom-up decision processes characterized by teams, the empowerment of multi-skilled workers on the shopfloor, demand-pull and horizontal decision mechanisms. These practices include Just-in-Time (JIT) and quality management practices such as quality circles (QC) and total quality management (TQM). While these practices continue to be effective under appropriate circumstances, the drastic appreciation of the Japanese yen that has taken place since the mid-1980s and the prolonged recession following the burst of the bubble have forced many Japanese manufacturers to adopt new methods to improve their production efficiency. In this paper we discuss one of such methods called Total Productivity Management (TPM). Unlike JIT or TQM, implementing TPM requires a top-down approach. TPM provides direct connections between corporate-wide objectives such as the overall cost reduction and shopfloor practices. It is possible that TPM has contributed significantly to Japanese manufacturers' recent success in reducing their cost of operation. (C) 1997 by John Wiley \& Sons, Ltd.
\end{abstract}

Manage. Decis. Econ. 18: 131-139 (1997)

No. of Figures: $1 \quad$ No. of Tables: 2 No. of References: 12

\section{INTRODUCTION}

It is well known that many of the manufacturing practices advanced in Japan in the 1970s and 1980s emphasize bottom-up decision processes characterized by teams, the empowerment of multi-skilled workers on the shopfloor, demand-pull and horizontal decision mechanisms. These practices include Justin-Time (JIT) and quality management practices such as total quality management (TQM). While these practices continue to be useful and effective under appropriate circumstances, the drastic appreciation of the Japanese yen that has taken place since the 1980s and the prolonged recession following the burst of the

* Correspondence to: Professor Masao Nakamura, Faculty of Commerce, University of British Columbia, 2053 Main Mall, Vancouver, BC V6T 1Z2, Canada. bubble have forced many Japanese manufacturers to adopt new methods to improve their production efficiency. ${ }^{1}$

In this paper we discuss one of such methods called Total Productivity Management (TPM). Unlike JIT or TQM, TPM employs a top-down approach. Many Japanese firms have implemented TPM for achieving well-defined corporate-wide objectives. The TPM procedure generally reduces such objectives to tangible and numerical targets, for example, for cost reduction for specific corporate activities.

By its nature, target setting and implementation processes of TPM require adjustments to be made up and down the value chain. For example, if a companywide goal required a $25 \%$ reduction in cost to produce a particular product, then appropriate 
adjustments in operations would have to be made not only in production areas but also in other functional areas such as design, logistics, marketing and sales. The top management must initiate undertaking target setting and implementation of such adjustments strategically, considering overall coordination and communication needs from the start. This is where TPM differs from the strong bottom-up emphasis of TQM.

It is of interest to note that Total Productivity Management is by no means the only top-down management method Japanese firms have adopted to increase their productivity. The notions put forward in Materials Requirements Planning (MRP) have been adopted by many Japanese firms. ${ }^{2}$ Many manufacturers have also adopted another top-down management practice entitled Total Productive Maintenance. ${ }^{3}$ While elements of these and other top-down approaches of technology management have been around and used in the Japanese manufacturing sector for some time, we believe that the present prolonged recession and increasingly keen international competition are forcing the Japanese manufacturers to take a fresh look at top-down approaches and introduce them with the purpose of explicitly tightening the connections between firm performance and shopfloor practices.

The post-bubble economic circumstances in Japan with few growth prospects has been particularly difficult for Japanese manufacturers who are still constrained by the traditional long-term employment practice and various keiretsu (corporate group) relationships. These business practices often prevent firms from restructuring by adopting flexible and timely decisions on employment and suppliers. The stable and unchanging workforce and suppliers, who are particularly helpful when firms face a growing product demand, often become a burden in a stagnant economy (Nakamura, 1993). Such an unchanging corporate environment creates undesirable behaviour such as complacency among workers managers and suppliers alike. Many of the recent adoptions of TPM by Japanese manufacturers clearly reflect the firms' desires to shake up their organizations so that such undesirable behavior which prevails in the firms' organization units can be destroyed.

While such campaigning effects of the TPM are undoubtedly an important reason for the adoption of TPM, we argue in this paper that the TPM itself has certain innovative features of technology management that, if combined with the now standard
Japanese-style practices such as JIT and TQM, could provide very powerful managerial tools for manufacturers in Japan as well as outside Japan.

The rest of the paper is organized as follows. In the next section we explain the general procedure for implementing TPM. In the third section we discuss a numerical example of an implementation of TPM at an appliance manufacturer. The fourth section briefly discusses Toshiba's experiences with implementing TPM in some of their factories. The paper ends with conclusions.

\section{TOTAL PRODUCTIVITY MANAGEMENT (TPM): A TOP-DOWN APPROACH}

The general procedure of TPM is summarized as follows:

- Step 1. Corporate goal setting: master schedule. Select companywide numerical goals and targets.

- Step 2. Top-down explosion process. Explode the master schedule (corporate-level goals and targets) systematically into actions by specific departments (or by specific product lines) and select numerical goals and targets for individual departments (or specific product lines). Repeat Step 2 until goals and targets are selected or assigned to all layers of relevant organizational units and individuals.

- Step 3. Implementation and assessment. Implement the overall plans. Compare the corporate performance with the originally set goals. Use the empirical information obtained in previous rounds of TPM in Step 2 of the next round.

It is clear that a successful implementation of TPM implies improvement in the immediately observable financial performance measures for which the original numerical goals and targets were set. The latter follows because of the direct (or definitional) connections that exist between the tasks to be implemented and the original company-wide goals and targets. (This is not to say that bottom-up procedures provide no direct financial benefits to the firm. See, for example, Nakamura, Sakakibara and Schroeder, 1996 for empirical evidence for the effects of JIT and TQM on plant performance in the US.)

It is also clear that an effective implementation of this top-down approach requires the full cooperation of all the employees involved. Yet it is often the lack of clearly defined incentive mechanisms for inducing 
such full cooperation from workers on the shopfloor and other stakeholders that has caused the failures of some implementations of Materials Requirements Planning (MRP). ${ }^{4}$

A substantial similarity between the formal procedures of TPM and MRP suggests that similar incentive issues exist for the implementation of TPM. The incentive mechanisms associated with the TPM procedure are not as well understood as the incentive mechanisms for Japanese bottom-up approaches such as JIT and TQM.

The TPM implementation process may also be interpreted as a process of organizational change (Fruin, 1997). For example, Etzioni's (1965, 1975) model of organizational change is based on cycles of compliance which refers to the conforming or nonconforming behavior of those who are in the midst of organizational change, measured against the expectations and performance goals of those in charge of planning and managing change. The model predicts that large-scale change activities move through a predictable sequence of four phases: education and promotion; commitment; performance; decline and withdrawal. The model does not, however, predict the duration, and hence timing by which phase succeeds one another.

In the context of the corporate productivity enhancement movement in Japan the above cycle of compliance will be referred to as a strategy cycle of a firm. The strategy cycle describes the process of firm's formation of strategic intent, followed by strategic implementation and strategic withdrawal. A successful strategy cycle requires a good balance between the various stages of identifying and setting goals, and then moving ahead to realize them, and to monitor progress along the way. Such balancing is made possible by a careful rollout of target and goals at every level of a firm, employing bottom-up approaches. Japanese firms that have successfully implemented TPM make judicious use of both top-down and bottom-up approaches, as we discuss below. ${ }^{5}$

\section{IMPLEMENTATION OF TPM}

Suppose that a manufacturer of refrigerators sets its firmwide TPM goal of developing a new product which embodies an improved level of customer satisfaction. In particular, they wish to double the commercial value of their product. Analysis of consumer surveys reveals that this goal can be achieved if their customers' perception of the product quality is increased by $80 \%$ and the product price is reduced by 10\%. (See Akiba, 1994, Ch.2, for a discussion on how firmwide goals such as improving customer satisfaction may be translated into tangible monetary terms such as reductions in cost and price.)

(a) The target of an $80 \%$ increase in the customers' perception of the product quality must be exploded ${ }^{6}$ into specific functions of a refrigerator that must be improved. Such improvements in the specific functions must also be priced out. In our case improvements of the following refrigerator parts will achieve our quality target: cooling mechanisms (estimated cost $=1300$ yen), box (400 yen), interior parts (1800 yen), door (200 yen), and controller (1300 yen). The quality perception target can be met with an added total cost of 5000 yen.

(b) It is necessary to achieve a $15 \%$ reduction in the unit production cost in order to achieve the target of an $10 \%$ reduction in the price. This means that the current production cost (200000 yen) must be reduced by $15 \%$ (30000 yen). Thus the total reduction in the production cost amounts to 35000 yen $(=5000+30000)$. Now it is necessary to explode this total cost reduction target into the specific cost-reduction targets for individual cost items: labor, raw materials, and overhead.

(c) The composition of the unit production cost is: labor $30 \%(60000$ yen $=200000 \times 0.3)$, raw materials $60 \%(120000=200000 \times 0.6)$, and overhead $10 \%(20000=200000 \times 0.1)$. After careful analysis, it was decided that the cost-reduction target, 35000 yen, will be allocated between labor and raw materials as follows: labor 14000 yen, and raw materials 21000 yen. These labor and raw materials cost reductions must now be exploded into specific numerical targets. We show below the explosion of the labor cost reduction.

(d) The explosion of the required labor cost reduction could be done, for example, along production workshops, labor functions, product lines, or worker tasks. After analysis we have decided to explode labor cost reduction target along five workshops: machine, molding, welding, assembly and inspection workshops. The assigned specific labor cost reduction targets are as follows (the present labor cost for each workshop is given in parentheses): machinery 4194 yen (18000 yen), molding 840 yen (4200), welding 2285 yen (9600), assembly 6000 yen (24000), and inspection workshop 660 yen (4200). We show below how we explode the cost-reduction target (6000 yen) for the assembly workshop.

(e) The assembly workshop has six continuous assembly lines A-F and two non-continuous produc- 
tion lines $\mathrm{G}$ and $\mathrm{H}$. Average labor input hours per month for these assembly lines are as follows: A (550 hours), B (982), C (1380), D (1007), E (1249), F (1272), G (155), and $H$ (109). The total number of input hours is 6704 hours per month. Lines B, C and E employ large labor hours, consist of similar job tasks and are likely to respond to some common treatments. We have decided to achieve our costreduction target for the assembly workshop by reducing the cost for these assembly lines. It was also decided that if cost reductions from lines B, C and $\mathrm{E}$ did not meet the workshop target, then we would try to make up the difference by exploding line $\mathrm{F}$ which seems to have some potential for cost reduction.

(f) The numerical target for cost reduction for the assembly workshop is 6000 yen. This corresponds to $25 \%$ of the total cost (24000 yen) for this workshop. Assuming that the hourly wage rate is constant for this workshop, we can rephrase our target in terms of hourly labor input. Our target is to reduce the current labor input (6704 hours) by 25\% (1676 hours). The past record shows that Lines $\mathrm{B}, \mathrm{C}$ and $\mathrm{E}$ are operational $95 \%$ of the time (a very high utilization rate) and hence our labor input reduction effort should be directed to machine running hours rather than their idle (down-) time. The total combined operational hours for these three lines are $(982+1380+1249) \times 0.95=3430$ hours. It was decided that a $40 \%$ reduction in this combined operational hours is feasible. That is, the target for labor input reduction for lines $\mathrm{B}, \mathrm{C}$ and $\mathrm{E}$ is 1372 hours $(=3430 \times 0.40)$. The balance of the reduction target for the assembly workshop (304 hours $=1676$ 1372) will be the target for line F.

(g) Labor input reduction for lines $B, C$, and $E$ : analysis. In order to find a feasible plane for meeting the required labor input reduction, we have decided to explode the reduction into specific activities called jobs that are done by lines B, C and E. Figure 1 shows a Gantt chart for 22 jobs (WI-W22) which form six production processes to be completed by lines $\mathrm{B}, \mathrm{C}$ and $\mathrm{E}$. The performance measure we use for these production processes is the make span which is defined to be the time to complete work of all six processes. The make span for the present sequencing given in Fig. 1 is 0.15 minute. Another measure of performance is labor utilization defined by the total utilized labor time ( 0.53 minutes) divided by the total labor time assigned to the work processes $(0.90$ minute). The current utilization rate is 0.589 $(=0.53 / 0.9)$. One way to achieve a $40 \%$ reduction in labor input without changing the number of jobs is to reduce the make span by $40 \%$ to 0.09 minute $(=0.15 \times(1-0.4))$.

(h) Labor input reduction for lines $B, C$ and $E$ : bottom-up jobs sequencing procedure. Processes 3 and 5 exceed the target make span (0.09 minute) by 0.01 and 0.06 minutes, respectively. Shopfloor analysis reveals that W11 can be transferred from processes 3 to 4 , and W19 and W20 can be transferred from processes 5 to 6 . After this rearrangement of job tasks process 5's duration time still exceeds the make span target by 0.02 minutes. Analysis of W15-18 which form process 5 reveals that job W18 can be done in 0.02 rather than

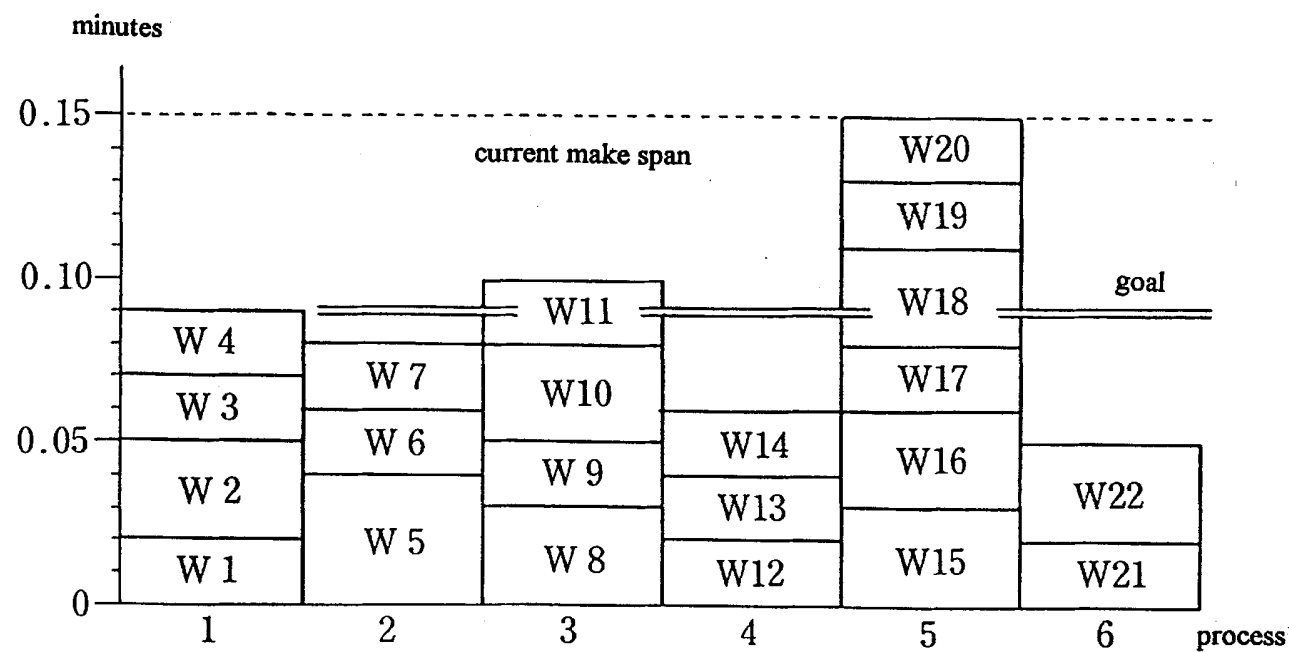

Figure 1. Gantt chart for lines B, C and D: 22 jobs in six processes. (Source: Akiba, 1994, p. 93.) 
0.03 minutes. This rearranged job sequencing provides a new make span of 0.09 minute. ${ }^{7}$

(i) Labor input reduction for line F: analysis. The target labor input reduction for line $\mathrm{F}$ is $23.9 \%$ $(=(304 / 1272) \times 100)$. Unlike lines B, C and E, the utilization rate of labor for line $\mathrm{F}$ is low and equal to $57.5 \%$. This suggests that our target may be achieved by reducing the idle time $(42.5 \%=100-57.5)$. Thus the target for line $\mathrm{F}$ is to reduce the idle time by $56.2 \%(=(0.239 / 0.425) \times 100)$. Analysis of idle time has revealed that there are two types of idle time which form total idle time. The total idle time $(42.5 \%)$ is divided into planned idle time $(12.3 \%)$ and downtime $(30.2 \%)$. It was then decided that $3.9 \%$ of the total labor input reduction target $(23.9 \%)$ will be allocated to a reduction in planned idle time while the remaining $20 \%$ will be assigned to a reduction in downtime. This means that planned idle time will be reduced by $31.7 \%(=0.039 / 0.123)$ and downtime will be reduced by $66.2 \%(=0.2 / 0.302)$.

(j) Labor input reduction for line F: bottom-up job sequencing procedure. In order to get specific targets the following time usage information was collected for idle time. Planned idle time $(12.3 \%)$ consists of setup time $(7.8 \%)$, machine adjustment time (1.8\%), morning greeting time $(1.3 \%)$ and other idle time $(1.4 \%)$. Downtime consists of idle time due to the late arrival of raw materials (1.4\%), machine downtime (4.2\%), raw materials waiting for processing $(21.1 \%)$ and other idle time (3.5\%). From shopfloor discussions and critical path analysis of specific tasks to be done we conclude that the reduction of the setup time from $7.8 \%$ to $3.9 \%$ and reduction of the raw material wait time from $21.1 \%$ to $1.1 \%$ are feasible and should be implemented.

The steps of the explosion explained above are illustrated in Tables 1 (steps (a)-(d)) and 2 (steps ((e)-(j)). Table 2 also illustrates other parts of the exploded process in our example. The implementation of a top-down TPM program requires substantial inputs of a bottom-up nature from the shopfloor, as we have shown in this example. First, a company- or factorywide goal is chosen. Such a goal is then translated typically into numerical targets for tangible cost reduction. As higher-level targets get exploded into specific numerical targets for relevant workshops and product lines, bottom-up cooperation from workers on the shopfloor is utilized. In fact without such a cooperation from the shopfloor no meaningful numerical targets could be derived and hence an effective implementation of any target would not be possible.

One of the main characteristics of TPM is that it deals with corporatewide goals. Another is that it deals with specific numerical targets for cost reduction. For example, a goal of product quality improvement gets translated into a cost-reduction figure as in the above example. This explicit recognition of the tradeoff between quality and cost has been standard in the Western thinking of manufacturing but has not been so until recently in Japan. $^{8}$

Such a quality-cost tradeoff must clearly exist at the corporate level even though it may be less visible

\section{Table 1. TPM Explosion (Cost Allocation) Process for the Corporate Goal to Achieve a Higher Level of Consumer Satisfaction: Development of a New Refrigerator, Part I}

TPM goal: increase consumer satisfaction $\rightarrow$ double commercial value $\rightarrow$ increase product quality perception by $80 \%$, reduce price by $10 \%$.

Unit production cost: $200000=60000$ (labor) +120000 (raw materials) +20000 (overhead).

Cost reduction target: $35000=5000$ (for improved quality) +30000 (required price reduction).

Cost increase due to $80 \%$ increase in product quality perception: $5000=$ cooling mechanism $(1300)+$ box $(400)+$ interior $(1800)+$ door $(200)+$ controller (1300). Cost reduction required for $10 \%$ price reduction: $30000=15 \%$ of 200000 .

\begin{tabular}{lll}
\multicolumn{3}{c}{ Explosion of the cost reduction target: $\mathbf{3 5 0 0 0}$} \\
labor: 60000 & raw materials: 120000 & overhead: 20000 \\
reduction target: 14000 & reduction target: 21000 & reduction target: 0 \\
$(40 \%)$ & $(60 \%)$ & $(0 \%)$
\end{tabular}

\begin{tabular}{lllll}
\multicolumn{5}{c}{ Explosion of the labor cost reduction target $(\mathbf{1 4} \mathbf{0 0 0}=\mathbf{4 0 \%})$ into workshop targets } \\
Machine WS & Molding WS & Welding WS & Assembly WS & Inspection WS \\
labor: 18000 & labor: 4200 & labor: 9600 & labor: 24000 & labor: 4200 \\
r.target: 4194 & r.target: 840 & r.target: 2285 & r.target: 6000 & r.target: 660 \\
$(12 \%)$ & $(2.4 \%)$ & $(6.5 \%)$ & $(17.2 \%)$ & $(2 \%)$
\end{tabular}

${ }^{\text {a }}$ See the text (Steps (a)-(d)) for details. 


\begin{tabular}{|c|c|c|c|c|c|c|c|}
\hline \multirow{2}{*}{$\begin{array}{l}\text { Workshop } \\
\text { (\%cost reduc. } \\
\text { target = AA) }\end{array}$} & \multicolumn{2}{|c|}{ Cost-reduction target } & \multirow{2}{*}{$\begin{array}{l}\text { Contribu- } \\
\text { tion to AA } \\
\text { (\% target) }\end{array}$} & \multicolumn{2}{|c|}{ Cost-reduction target } & \multirow{2}{*}{$\begin{array}{l}\text { Cost-reduction target } \\
\text { Task Object } \\
\text { (\% reduction) }\end{array}$} & \multirow{2}{*}{$\begin{array}{l}\text { Specific targeted } \\
\text { actions/jobs } \\
\text { (\% reduction) }\end{array}$} \\
\hline & Task & Object (\% reduction) & & Task & $\begin{array}{l}\text { Object } \\
\text { (\% reduction })\end{array}$ & & \\
\hline \multirow[t]{4}{*}{$\begin{array}{l}\text { Machine } \\
(12 \%)\end{array}$} & $\begin{array}{l}\text { Milling } \\
\text { machine }\end{array}$ & Labor hours (25\%) & 1.65 & & & & $\begin{array}{l}\text { Workers' waiting } \\
\text { (idle) time }(80)\end{array}$ \\
\hline & L. press & Labor hours (20\%) & 3.23 & $\begin{array}{l}\text { Processes A, C, } \\
\text { D }\end{array}$ & $\begin{array}{l}\text { Labor hours } \\
\text { (34) }\end{array}$ & & $\begin{array}{l}\text { Raw materials } \\
\text { delivery time ( } 85)\end{array}$ \\
\hline & S. press & Labor hours (20\%) & 3.23 & Processes X, Y & $\begin{array}{l}\text { Labor hours } \\
(30)\end{array}$ & & Press time (45) \\
\hline & $\begin{array}{l}\text { Pipe } \\
\text { fitting }\end{array}$ & Labor hours (30\%) & 2.39 & & & & $\begin{array}{l}\text { Time to install } \\
\text { pipes to machine } \\
\text { (47) }\end{array}$ \\
\hline $\begin{array}{l}\text { Molding } \\
(2.4 \%)\end{array}$ & & Cycle time & 2.40 & & & & $\begin{array}{l}\text { Delivery time of } \\
\text { molded products } \\
\text { by cart }(30)\end{array}$ \\
\hline \multirow[t]{2}{*}{$\begin{array}{l}\text { Welding } \\
(6.5 \%)\end{array}$} & & Welding time (25\%) & 4.45 & & & & $\begin{array}{l}\text { Tool handling } \\
\text { time (40) }\end{array}$ \\
\hline & & Setup time $(34 \%)$ & 1.25 & & & & $\begin{array}{l}\text { Delivery/ } \\
\text { preparation time } \\
\text { of materials (50) }\end{array}$ \\
\hline \multirow[t]{2}{*}{$\begin{array}{l}\text { Assembly } \\
(17.2 \%)\end{array}$} & $\begin{array}{l}\text { Lines } \\
\text { B, C, E }\end{array}$ & $\begin{array}{l}\text { Operation time } \\
(40 \%)\end{array}$ & 14.1 & & $\begin{array}{l}\text { Make span } \\
\text { time (14.1) }\end{array}$ & & $\begin{array}{l}\text { Prod. Y. assembly } \\
\text { time (14.1) }\end{array}$ \\
\hline & Line $F$ & Total time $(23.9 \%)$ & 3.1 & & $\begin{array}{l}\text { Idle time } \\
(3.1)\end{array}$ & $\begin{array}{l}\text { Planned idle time } \\
(31.7) \\
\text { Target } 0.5 \\
\text { Downtime }(66.2) \\
\text { Target } 2.6 \%\end{array}$ & $\begin{array}{l}\text { Raw materials } \\
\text { waiting time } \\
(94.8)\end{array}$ \\
\hline $\begin{array}{l}\text { Inspection } \\
(2 \%)\end{array}$ & & $\begin{array}{l}\text { Reduce the number } \\
\text { of workers in WS } \\
\text { from } 8 \text { to } 6\end{array}$ & 1.7 & & & & $\begin{array}{l}\text { Workload during } \\
\text { downtime (90) }\end{array}$ \\
\hline
\end{tabular}

The explosion process proceeds from left to right. See the text (Steps (e)-(j)) for details.

from the shopfloor. Bottom-up approaches to manufacturing problems may only provide sub-optimal solutions from the firm's perspective when a corporate-wide optimal solution is required. While solving some sub-optimization problems on the shopfloor leads to immediate reductions in product cost and hence to increase in company-wide profits, solving others may not lead directly to improvements in company-wide performance measures. It is in this environment that TPM has been found to be effective for overall optimization and hence for improving firms' overall profitability.

\section{TPM AT TOSHIBA}

Toshiba, like most other Japanese manufacturers, maintains most of their productive resources in operational facilities such as factories and divisional laboratories. (Such laboratories are typically found in factories.) Employees on the shopfloor (which is often the lowest level within the corporate hierarchy) have a strong voice in the company but may see little connection between what they do and how and where the company makes money. Hence there is much room for their sub-optimizing behavior. The TPM approach provides these employees with targets (for example, for cost reduction) which are directly connected to the corporate profits in a top-down manner. TPM at Toshiba is intended to encourage the employees of all levels to focus on the companywide profits rather than the local cost of production, to become more involved, participate more, and be more ambitious.

It is particularly interesting to note that TPM at Toshiba began at its Mie Works in 1978 when the 
Works Manager recognized that most of the gains from TQM and quality circles (QC) were already in the bank and new gains from TQM and QC would be less substantial. Toshiba adopted a companywide Total Productivity (TP) campaign in 1985. It was followed by a STEP (Software, Technology and Excellent Products) campaign in 1987 and an ISM (Innovation in Sales and Marketing) campaign in 1989. These are timed companywide campaigns, designed to dovetail one with another. This illustrates that Toshiba and other Japanese firms use TP and other work improvement campaigns not only for enhancing companywide productivity but also for breaking the complacency which tends to prevail in the workplace where little personnel change takes place. (See Fruin, 1997, Ch. 3.)

Thus, while the functional emphasis of campaigns might shift from production, technology, and then to sales and marketing, the themes and efforts of earlier campaigns are not neglected. They are simply rolled up into the next campaign as one more level of integration within an overarching campaign strategy. Toshiba has found that maintaining thematic continuity and consistency in method is key to campaign success. By 1991 more than 300 full-time equivalent employees are working on TP issues in Toshiba's 27 domestic factories.

\section{TPM at Yanagicho Works}

The Yanagicho Works is 60 years old, the third oldest among all Toshiba Works, and employs some 3000 regular workers. In addition to the production lines for plain paper photocopiers (PPC), labor-saving machines such as automated teller machines (ATM) and automated mail sorters, and other final products, the Yanagicho Works includes facilities and workers for development of experimental and new products. The Works has 20 departments, 20 department managers and more than 80 section managers. The TP movement at Yanagicho Works is handled by three managers who work full-time for the TP rollout.

\section{Machine Tool Department}

The main work of this department at the Yanagicho Works is the design and maintenance of tools, dies, and molds used in the manufacture and assembly of all sorts of Yanagicho products. Because of short development and design cycles for some products and limited response capabilities of suppliers to
Toshiba's needs, Yanagicho continually assesses what should be made in-house and what should be outsourced. In 1988 the department set a target for reducing lead times for delivering PPC frame side panels and molds to the PPC department by $25 \%$ from 21 days in 1987 to 15 days in 1990. Given this target the following action plans were adopted for improving the speed and efficiency with which work was accomplished, the use of machine tools and setup times, productivity, and quality. The target was achieved.

\section{Labor-savings Equipment Department}

This department at the Yanagicho Works produces most products to order and hence the most important performance measure is the lead time between when the customer places an order and when the company delivers the product. Reducing machine setup time for mold and die changeovers is particularly important. The percentage of the setup times below 10 minutes went up from $90 \%$ in 1986 to $98 \%$ in 1989. This increased the shipment value from the department from $\$ 290$ per hour to $\$ 430$ per hour.

\section{TPM at Ome Works}

Ome Works was established in 1968 and produces various types of computers ranging from minicomputers to palm-size personal computers. One of the most successful products at Ome Works is Toshiba laptops, the sales of which has been in the range of 60000-70000 units per month since 1989 . Toshiba laptops claimed the largest share of the North American laptop market in 1995 with nearly a half-million units sold.

At Ome TPM has focused on integrating the two aspects of plant operations: linking all the factory's activities in a fiber-optic-based computer-integrated manufacturing (CIM) system for improving the factory's information processing and planning capabilities; and developing a production system that closely follows the rate of sales for many of the computer products produced at Ome.

The results of the first TPM effort at Ome was the development of End-User Computing (EUC). EUC was strategy to enable all Ome employees to have access to a real-time database by interlacing LANs and laptop computers throughout the factory's many functional and product departments. The real-time database included information on development, production and marketing lead times such as design 
milestones for new products under development, work-in-progress inventories for every product and model, production schedules, sales trend, and parts and component availability. The aim is, by providing relevant information to all employees in planning, supply, design, development, manufacturing, shipping, sales and production, to bring the right products to market at right time. With the implementation of EUC Ome Works became able to produce a larger number of differentiated computer products in smaller lot sizes, thus advancing the state of the art in JIT manufacturing.

The actual implementation of EUC was achieved gradually. Various sections in different product departments were designated as 'model shops', and they were brought onstream as a part of their routine organization campaign activities. Numerical targets and goals that were introduced include: reductions in set-up times and in work-in-progress inventories; greater use of kanban and kit marshaling; improvements in component and unit assembly operations; automation of difficult and dangerous tasks; and more intensive applications of industrial engineering knowhow in production.

The effects of the introduction of EUC were significant. For example, after the introduction of EUC in 1988, the hourly productivity of production workers increased by an average of $16 \%$ per year; and, during the 1988-92 period, work-in-process and sales inventories were reduced by one-seventh and one-fifth, respectively, for Japanese word processors (special-purpose personal computers). Ome Works is now able to manage their manufacturing knowledge in almost real-time.

\section{CONCLUSIONS}

With Just-in-Time and TQM bottom-up practices having been around for many years, Toshiba, like other Japanese manufacturers, needs new campaigning approaches to begin non-routines. Such needs are particularly imminent for Japanese firms facing a high yen, a stagnant domestic economy and keen global competition. It is under these circumstances that Japanese manufacturers are experimenting with the top-down TPM approach which provides explicit connections between corporate performance and shopfloor practices.

TPM differs from TQM and other bottom-up approaches of production management not only in its cost-reduction emphasis but also in the degree to which companies want their employees to be more aware of the way in which their efforts contribute to the whole. Whereas TQM activities are quite particularistic in that no two employees are doing exactly the same task, in TPM there are many employees in many departments and section doing the same thing even though their particular tasks and numerical targets may differ.

We have noted that the TPM procedure, which connects firm performance to specific tasks, production processes and workers, appears similar to the procedure employed by Materials Requirements Planning. Both TPM and MRP seek corporate- or factorywide optimal production settings. However, the TPM procedure, unlike the MRP procedure, has some components that are explicitly bottom-up. In particular, TPM requires bottom-up consultation for both setting targets and inducing worker cooperation from the shopfloor for implementing set targets.

It is possible that many reported successful applications of TPM and other top-down methods of productivity enhancement have contributed significantly to Japanese manufacturers' recent successes in reducing their production and transaction costs. It is interesting to see if these methods continue contributing to strengthening Japanese manufacturers' global competitiveness which has been severely damaged in the last decade.

\section{Acknowledgements}

This research has been in part supported by the Social Sciences and Humanities Research Council of Canada.

\section{NOTES}

1. The production settings where a pull system like JIT is suitable is discussed, for example, in Aoki (1988).

2. See, for example, Schroeder (1993, Ch. 7) for a description of Materials Requirements Planning.

3. Total Productive Maintenance (Nakajima, 1988; Suzuki, 1994) emphasizes the preventive maintenance function of plant and equipment. (The importance of the maintenance function is also recognized internationally, for example, by the European Federation of National Maintenance and the American Institute of Total Productive Maintenance.) Various applications of Total Productive Maintenance reported in Suzuki (1994) indicate that the stated goals of Total Productive Maintenance practices are closely tied to manufacturing quality performance which is often restated, in implementation, in monetary figures such 
as cost and value added. Total Productive Maintenance is reported to have been implemented in some of Japanese firms' overseas operations also. (For example, at Toyota Gosei USA and Waterville Toyota Gosei in Canada (Nemoto, 1992.) For all practical purposes, however, many of the practices implied by adoption of the Total Productive Maintenance procedure are indistinguishable from the Total Productivity Management practices we discuss below. It is our view that the procedure of Total Productivity Management is somewhat more general and systemic than that of Total Productive Maintenance.

4. For example, Schroeder (1993, p. 654) notes that both system and people problems must be solved to use MRP successfully.

5. Many of these Japanese manufacturers use TPM, JIT and TQM. Many also use Total Productive Maintenance. This is also consistent with the joint use by many US manufacturers of MRP and JIT (Schroeder, 1993, Ch. 18).

6. This process is very similar to parts explosion in MRP (Schroeder, 1993) and hence we use the same term here. Another English word that describes this process is deployment, as is used in quality function deployment.

7. More general algorithms for optimal job sequencing and project management could be used here. (See, for example, Schroeder, 1993, Ch. 14.)

8. Toyota asked Arthur D. Little to estimate the cost of producing cars in the US in the early 1980s. ADL consultants approached this cost-estimation task by treating cost and quality separately. They argued that as quality requirements increased, the production cost would also increase accordingly. Their notion of quality is consistent with the concept of quality prevailing at that time in the US manufacturing industries. The notion then was that as one tries to reduce the number of defective cars to be picked out at the final inspection station, the cost must increase. As is well known, Toyota's JIT manufacturing rejects such a notion. Toyota argued that higher quality could be achieved with no additional cost.

\section{REFERENCES}

M. Aoki (1988). Information, Incentives, and Bargaining in the Japanese Economy, New York: Cambridge University Press.

M. Akiba (1994). Total Productivity Management (TP management no susumekata), Tokyo: J Nihon Noritsu Kyokai Management Centre (in Japanese).

A. Etzioni (1965). Political Unification: A Comparative Studies of Leaders and Forces, New York: Holt, Reinehart, and Winston.

A. Etzioni (1975). A Comparative Analysis of Complex Organizations, New York: Free Press.

W. M. Fruin (1996). Manufacturing knowledge in Japan: organization campaigning and time-based management. Paper presented at the PRISM 1996 summer meeting, Seattle.

W. M. Fruin (1997). Knowledge Works: Managing Intellectual Capital at Toshiba, New York: Oxford University Press, forthcoming.

S. Nakajima (1988). Introduction to Total Productive Maintenance, Portland, OR: Productivity Press.

M. Nakamura (1993). Japanese industrial relations in an international business environment. North American Journal of Economics and Finance, 225-51.

M. Nakamura, S. Sakakibara and R. G. Schroeder (1996). Japanese manufacturing methods at U.S. manufacturing plants: empirical evidence. Canadian Journal of Economics, 29, S468-74.

M. Nemoto (1992). 30 Musts for Successful TQC, Tokyo: Nikka Giren (JUSE).

R. G. Schroeder (1993). Operations Management: Decision Making in the Operations Function, New York: McGraw-Hill.

T. Suzuki (1994). TPM and Concurrent Engineering: Reducing Product Development Lead Time (TPM to Concurrent Engineering: seihin kaihatsu lead time no tanshuku), Nihon Plant Maintenance Kyokai/Nihon Noritsu Kyokai Management Centre (in Japanese). 